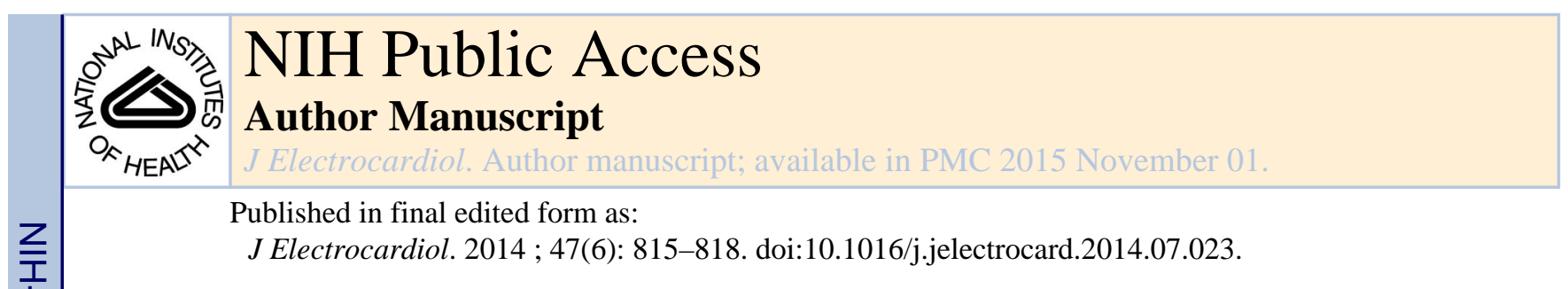

\title{
Racial differences in sudden cardiac death
}

Erin A. Fender, MD ${ }^{1}$, Charles A. Henrikson, MD, MPH ${ }^{1}$, and Larisa Tereshchenko, MD, PhD1

${ }^{1}$ The Knight Cardiovascular Institute, Oregon Health \& Science University, Portland, OR; USA

\begin{abstract}
There is an increased risk of sudden cardiac death (SCD) and sudden cardiac arrest (SCA), in African Americans, the basis of which is likely multifactorial. African Americans have higher rates of traditional cardiac risk factors including hypertension, left ventricular hypertrophy, diabetes, coronary heart disease, and heart failure. There are also significant disparities in health care delivery. While these factors undoubtedly affect health outcomes, there is also growing evidence that genetics may have a significant impact as well. In this paper, we discuss data and hypotheses in support of both sides of the controversy around racial differences in SCD/SCA.
\end{abstract}

\section{Racial differences in the rate of sudden cardiac death}

Sudden cardiac arrest (SCA) and sudden cardiac death (SCD) disproportionally impacts African Americans in every age group, as compared with Caucasians (1-3). The increased risk of SCA and coronary heart disease has traditionally been attributed to the most prevalent risk factors (hypertension (4), left ventricular hypertrophy (5), heart failure, obesity, and diabetes mellitus) in African Americans (6). The survival rate after out-ofhospital cardiac arrest amongst African Americans is about one-third that of Caucasians (2, $3,7)$. The reasons for the observed disproportionality are complex and could be considered in 2 realms: socioeconomic and genetic.

\section{Socioeconomic factors and racial disparities}

There are significant racial disparities in the delivery of cardiac health care. In a recent American Heart Association survey, 90\% of African Americans reported that their doctors had never discussed their risk for cardiac death, and $60 \%$ of African American patients who actually experienced heart disease symptoms reported that they did not seek medical care(8). Additional research has demonstrated that lifesaving therapies such as implantable cardioverter-defibrillators (ICDs) are underutilized in African Americans(9). While there has been an overall trend towards improved utilization of ICDs in all survivors of SCD (10), African American patients are still less likely than Caucasians to receive an ICD for primary prevention of SCA (11).

The neighborhood in which a person suffers SCA may dramatically affect the odds of survival. This is in part due to lower rates of bystander cardiopulmonary resuscitation (CPR)

Correspondence to Larisa Tereshchenko, 3181 SW Sam Jackson Park Rd; UHN62; Portland, OR, 97239. tereshch@ ohsu.edu. Phone: 503-494-7400; Fax: 503-494-8550. 
in low income and more racially diverse areas. Barriers to learning CPR are multifactorial and include health care literacy, access to health education and training, motivation, and fear of legal consequences (12).

On a population level, African Americans generally have less access to health care and a higher incidence of obesity, smoking, hypertension and heart disease. Black race, lower educational attainment, and low neighborhood socio-economic status (SES) are independently associated with an increased incidence of SCD (13), and even with increased relative risk of sudden as compared to non-sudden cardiac death (14). Differences in cardiovascular risk profiles (15), different levels of psychological stress (16), as well as less access to primary care and emergency medical services, all contribute to the association between low SES and increased risk of SCD. Importantly, a recent study compared the impact of socialized medicine on the incidence of SCD in patients with low SES(17). The private health care insurance system of the United States was compared to the publically funded universal access health system in Finland. Surprisingly the study found no difference in the incidence of SCD in low income areas, implying that the social and economic factors responsible for the increased incidence of SCD in individuals with low SES operate similarly despite differences in health care delivery (17).

\section{Genetic factors}

Substantial data indicates that genetic variants predisposing to SCD may be more prevalent in African Americans. Genomic analysis has demonstrated ethnic variation in the alleles encoding cardiac potassium and sodium channels which are associated with J-point elevation (JPE), the Brugada syndrome (BrS), and long QT syndromes (LQTS). In 2003 Ackerman et al (18) screened 744 asymptomatic subjects for variants in the potassium rectifier genes associated with congenital LQTS, including 305 African Americans, 187 Caucasians, 134 Asians (comprised of people of Japanese, Chinese, and Filipino descent), and 118 Hispanics. Gene mutation analysis of KCNQ1, KCNH2, KCNE1, and KCNE2 yielded 49 distinct amino acid sequences, of which 53\% were observed exclusively in African American subjects. Excluding common polymorphisms, 25\% of African Americans and $14 \%$ of Caucasians had at least 1 nonsynonymous (i.e. with altered amino acid sequence of a protein) potassium channel $(\mathrm{P}<0.1)$.

Racial differences in the alpha subunit of the $I_{\mathrm{n}}$ channel encoded by SCN5A have also been described. Mutations in SCN5A have been implicated in both BrS1, and LCT3. A 2004 survey of SCNA5 mutations in asymptomatic adults identified 39 missense variants (meaning single nucleotide change resulted in a different amino acid), $49 \%$ of which were seen only in the African American cohort $(18,19)$. Four of the 39 polymorphisms were entirely race specific, including the Y1102 allele which was seen exclusively in African Americans.

A 2002 study by Splawski et al also found significant racial variations in the prevalence of the Y1102 mutation (20). The Y1102 mutation was observed in 19.2\% West Africans and Caribbeans, and 13.2\% African Americans, but not in any subject in the control group of 511 Caucasians and 578 Asians. Analysis of a second group of African Americans with a 
history of syncope, aborted SCD, ventricular tachycardia, and medication or bradycardia associated QT prolongation, demonstrated an even higher incidence of the Y1102 mutation. In the group with the pro-arrhythmia phenotype the incidence of Y1102 was 56.6\%, as compared to $13 \%$ in healthy African American controls (20). The association between Y1102 and the risk for SCD was further borne out by Burke et al (21) who performed post mortem genetic sequencing on tissue samples taken from African Americans, including 107 non-cardiac controls and 25 patients who suffered SCD. The Y1102 polymorphism frequency was $5.6 \%$ in the noncardiac deaths, and $28 \%$ in the unexplained arrhythmia deaths. After adjusting for age and sex, the relative risk for unexplained arrhythmic death in the Y1102 group was 8.4 (confidence interval (CI) 2.1-28.6, $\mathrm{P}=0.001$ ).

Splawski et al (20) studied the effect of the Y1102 mutation on the action potential in transfected human kidney cells and demonstrated only a subtle impact on gating and action potentials. However, when they simulated a block of the rapidly activating delayed rectifier potassium currents $\left(I_{\mathrm{Kr}}\right)$, which is a common side effect of many medications and hypokalemia, they were able to model that the Y1102 mutation would result in action potential prolongation (QT prolongation) and early after depolarizations-known triggers for ventricular tachycardia. This finding was then confirmed by Akylbekova et al (22) in analysis of the 4,476 African American participants enrolled in the Jackson Heart Study. The Y1102 allele was seen in $15.4 \%$ of participants and was independently associated with QT prolongation (2.7 milliseconds; P <.001). The duration of QT prolongation in Y1102 carriers increased further in the setting of hypokalemia (14.6 milliseconds; $\mathrm{P}=0.02$ ).

J-point elevation (JPE) is a general term for different conditions with dissimilar prognosis and outcomes. Both J-waves and J-point elevation (JPE) with a notch or slur have been associated with an increased risk of ventricular fibrillation and polymorphic ventricular tachycardia in several studies (23-25). At the same time, J-point elevation known as benign early repolarization, is a common finding in healthy young people and is particularly prevalent in patients of African descent. Both J-waves and malignant JPE have been linked in functional studies to the transient outward potassium channel $\left(I_{\mathrm{to}}\right)$, which is encoded by KCND3. Mutational analysis of KCND3 in patients with clinical $\mathrm{BrS}$ but negative genetic testing for the eight known BrS susceptibility genes have implicated a gain of function mutations in this gene. However, more complete genetic surveys of polymorphisms in KCND3 are lacking, and it is unclear if these polymorphisms can result in isolated JPE. Given the racial variability seen in other sodium and potassium channel genes, it is likely that there is significant ethnic variability in KCND3 which may potentially account for the increased incidence of JPE seen in African Americans.

As discussed above, there is a growing body of evidence that racially specific genetic polymorphisms in cardiac ion channel genes may predispose to an increased risk of malignant arrhythmias, and therefore SCD. In contrast to these findings, a recent genomewide association study of the QT interval in African American and Caucasian $(n=13,105)$ failed to demonstrate that genetic indices of African ancestry were independently correlated with the duration of cardiac repolarization(26). It is notable that the incidence of specific polymorphisms in cardiac ion channel genes was not examined by this study. However, this study does raise an important point- that ancestry alone may not impart increased risk. Given 
the findings of both Ackerman et al and Splawski et al, it is clear that additional research into the role of genetic polymorphisms, and phenotypic predisposition to ventricular arrhythmias is warranted $(18,20,21)$.

\section{Bi-racial cohorts reporting J-point amplitude}

The observation that multiple ECG variations occur at increased frequency in non-whites has been reported by several large cohort studies (Table 1). It is important to note that the studies included in Table 1 used various definitions for both the J-point and JPE, which may introduce significant variability in the incidence of JPE observed in the population. In 1993 Sutherland et al (27) reviewed 2,181 ECGs obtained as part of the Charleston Heart Study (CHS) and examined the association between race, baseline ECG findings, and mortality over the ensuing 30 years. Using the Minnesota Code (MC), 13.7\% of African American men were found to have major abnormalities in the baseline ECG as compared to $6.9 \%$ of Caucasian men ( $\mathrm{P}<0.01)$. Specific ECG abnormalities which occurred more commonly in African Americans included $\mathrm{T}$ wave flattening or inversions, high amplitude $\mathrm{R}$ waves, left axis deviation, $\mathrm{LVH}$ voltage criteria, nonspecific T or ST changes, and 'early repolarization'. Early repolarization was reported in $11.3 \%$ of Caucasian men and $32.7 \%$ of African American men. After controlling for coronary artery disease (CAD) risk factors and minor ECG abnormalities, a statistically significant increased risk of death from CAD was observed only in Caucasians with major ECG criteria (RR 2.72, CI 1.47-5.04) and not African Americans (RR 1.95, CI 0.93-4.11). Early repolarization was not associated with increased all-cause mortality in either race.

A 1998 sub group analysis of the Atherosclerosis Risk in Communities Study (ARIC) cohort assessed ECG findings in 2,686 healthy African American and Caucasian men and women between the ages of 45 and 64. By MC criteria, $46 \%$ and 32\% of African American men and women respectively were classified as having minor ECG findings, whereas $25 \%$ of Caucasian men and 23\% of Caucasian women had minor ECG findings (28). After adjusting for covariants, the authors found statistically significant differences in multiple ECG variables, including $\mathrm{J}$ point amplitude in $\mathrm{V}_{2}$ and $\mathrm{V}_{5}$. For African American men, the $\mathrm{J}$ wave amplitude was higher than Caucasian men by an average of $45 \mu \mathrm{V}$ in $\mathrm{V}_{2}$ and $25 \mu \mathrm{V}$ in $\mathrm{V}_{5}$. Similarly, African American women were observed to have 16 and $22 \mu \mathrm{V}$ higher J-point amplitudes than Caucasian women in leads $\mathrm{V}_{2}$ and $\mathrm{V}_{5}$. Later Olson et al showed that JPE was associated with increased risk of SCD in Caucasians, but not in African-Americans(29).

One critique of both the Charleston Heart Study and the ARIC cohort was the majority of African American participants were enrolled from a narrow geographic region in the South. As a result, participants may have had lower SES, less access to medical care, and increased rates of smoking, diabetes and obesity. Therefore, the increased incidence of major and minor ECG changes seen in African Americans may actually be a surrogate marker for poor cardiovascular health. The authors' findings may not be generalizable despite attempts to correct for both co-morbid conditions and social factors. Two more recent cohort studies attempted to address this major confounder by drawing from a geographically diverse population. Prineas et al (30) analyzed ECGs obtained from participants in the Reasons for Geographic and Racial Difference in Stroke Study (REGARDS) cohort. Subjects were 
randomly recruited from across the United States. ECGs from 20,962 African American and Caucasian subjects were analyzed using the MC. In the total population, $28.2 \%$ had at least one major ECG abnormality. In the 45 to 65 year old age group, African American men and women had an increased incidence of major ECG findings relative to Caucasians, but this difference equalized in the $>65$ year old age group, with Caucasians and African Americans having a similar incidence of $\mathrm{MC}$ abnormalities. Of note, ST segment elevation was reported in 192 of 20,962 subjects. However, this finding was near exclusively seen in African American men under age 65, 6.3\% of whom had JPE, compared to only $1.3 \%$ of Caucasian men under the age of 65 .

Walsh et al (31) reviewed ECGs obtained from 2,585 subjects enrolled in the Coronary Artery Risk Development in Young Adults (CARDIA) cohort. The study population was on average 45 years old and enrolled from 4 cities, including Birmingham AL, Chicago IL, Minneapolis MN, and Oakland CA. Patients were followed prospectively for 20 years. Major ECG abnormalities were observed in 13.2\% of African Americans compared to 6.1\% of Caucasians ( $\mathrm{p}<.0001$ ), and minor ECG abnormalities were seen in $24 \%$ of African Americans versus $9.2 \%$ of Caucasians ( $p .0001)$. As in the REGARDS cohort, significant racial differences in major and minor ECG criteria were observed in the 45 to 65 year old cohort, and the observed racial differences in ECG findings persisted after multivariate adjustment for CAD risk factors..

The findings of these cohorts demonstrate significant racial variations in ECG findings which were not correlated with CAD risk factors or increased risk of adverse cardiac outcomes. The increased incidence of ECG changes in African Americans may not simply be a surrogate for cardiac health, but instead represent the results of mechanistic differences in cardiac electrophysiology. This suggests that interpretation of 'normal' ECGs should account for both age and racial background. However, guideline criteria for race specific ECG interpretation are lacking.

In summary, data suggests that a complex interplay of socio-economic factors, comorbidities, and genetics are responsible for an increased risk of SCD in African Americans. In addition to efforts to address health care disparities and comorbidities, further research is needed into the role of genetics in order to address develop race-specific prediction and prevention of SCD strategies.

\section{Acknowledgments}

This work was partially supported by the National Institutes of Health (1R01HL118277 to Tereshchenko).

Financial support: This work was partially supported by the National Institutes of Health (1R01HL118277 to LGT)

\section{References}

1. Adabag AS, Peterson G, Apple FS, Titus J, King R, Luepker RV. Etiology of sudden death in the community: results of anatomical, metabolic, and genetic evaluation. AmHeart J. 2010; 159:33-39.

2. Becker LB, Han BH, Meyer PM, Wright FA, Rhodes KV, Smith DW, Barrett J. Racial differences in the incidence of cardiac arrest and subsequent survival. The CPR Chicago Project. NEnglJMed. 1993; 329:600-606. 
3. Cowie MR, Fahrenbruch CE, Cobb LA, Hallstrom AP. Out-of-hospital cardiac arrest: racial differences in outcome in Seattle. AmJPublic Health. 1993; 83:955-959.

4. Hertz RP, Unger AN, Cornell JA, Saunders E. Racial disparities in hypertension prevalence, awareness, and management. ArchInternMed. 2005; 165:2098-2104.

5. Drazner MH, Dries DL, Peshock RM, Cooper RS, Klassen C, Kazi F, Willett D, Victor RG. Left ventricular hypertrophy is more prevalent in blacks than whites in the general population: the Dallas Heart Study. Hypertension. 2005; 46:124-129. [PubMed: 15939807]

6. Okin PM, Kjeldsen SE, Julius S, Dahlof B, Devereux RB. Racial differences in sudden cardiac death among hypertensive patients during antihypertensive therapy: the LIFE study. Heart Rhythm. 2012; 9:531-537. [PubMed: 22079554]

7. Chan PS, Nichol G, Krumholz HM, Spertus JA, Jones PG, Peterson ED, Rathore SS, Nallamothu BK. Racial differences in survival after in-hospital cardiac arrest. JAMA. 2009; 302:1195-1201. [PubMed: 19755698]

8. Groeneveld PW, Heidenreich PA, Garber AM. Racial disparity in cardiac procedures and mortality among long-term survivors of cardiac arrest. Circulation. 2003; 108:286-291. [PubMed: 12835222]

9. Hernandez AF, Fonarow GC, Liang L, Al-Khatib SM, Curtis LH, LaBresh KA, Yancy CW, Albert NM, Peterson ED. Sex and racial differences in the use of implantable cardioverter-defibrillators among patients hospitalized with heart failure. JAMA. 2007; 298:1525-1532. [PubMed: 17911497]

10. Saba S, Ravipati LP, Voigt A. Recent trends in utilization of implantable cardioverter-defibrillators in survivors of cardiac arrest in the United States. Pacing ClinElectrophysiol. 2009; 32:1444-1449.

11. Mezu U, Ch I, Halder I, London B, Saba S. Women and minorities are less likely to receive an implantable cardioverter defibrillator for primary prevention of sudden cardiac death. Europace. 2012; 14:341-344. [PubMed: 22071382]

12. Sasson C, Haukoos JS, Bond C, Rabe M, Colbert SH, King R, Sayre M, Heisler M. Barriers and facilitators to learning and performing cardiopulmonary resuscitation in neighborhoods with low bystander cardiopulmonary resuscitation prevalence and high rates of cardiac arrest in Columbus, OH. CircCardiovascQualOutcomes. 2013; 6:550-558.

13. Nichol G, Thomas E, Callaway CW, Hedges J, Powell JL, Aufderheide TP, Rea T, Lowe R, Brown T, Dreyer J, Davis D, Idris A, Stiell I. Regional variation in out-of-hospital cardiac arrest incidence and outcome. JAMA. 2008; 300:1423-1431. [PubMed: 18812533]

14. Escobedo LG, Zack MM. Comparison of sudden and nonsudden coronary deaths in the United States. Circulation. 1996; 93:2033-2036. [PubMed: 8640979]

15. Hinkle LE Jr, Thaler HT, Merke DP, Renier-Berg D, Morton NE. The risk factors for arrhythmic death in a sample of men followed for 20 years. AmJ Epidemiol. 1988; 127:500-515. [PubMed: 3341356]

16. Lynch JW, Kaplan GA, Cohen RD, Tuomilehto J, Salonen JT. Do cardiovascular risk factors explain the relation between socioeconomic status, risk of all-cause mortality, cardiovascular mortality, and acute myocardial infarction? AmJ Epidemiol. 1996; 144:934-942. [PubMed: 8916504]

17. Kucharska-Newton AM, Harald K, Rosamond WD, Rose KM, Rea TD, Salomaa V. Socioeconomic indicators and the risk of acute coronary heart disease events: comparison of population-based data from the United States and Finland. Ann Epidemiol. 2011; 21:572-579. [PubMed: 21737046]

18. Ackerman MJ, Tester DJ, Jones GS, Will ML, Burrow CR, Curran ME. Ethnic differences in cardiac potassium channel variants: implications for genetic susceptibility to sudden cardiac death and genetic testing for congenital long QT syndrome. Mayo ClinProc. 2003; 78:1479-1487.

19. Ackerman MJ, Splawski I, Makielski JC, Tester DJ, Will ML, Timothy KW, Keating MT, Jones G, Chadha M, Burrow CR, Stephens JC, Xu C, Judson R, Curran ME. Spectrum and prevalence of cardiac sodium channel variants among black, white, Asian, and Hispanic individuals: implications for arrhythmogenic susceptibility and Brugada/long QT syndrome genetic testing. Heart Rhythm. 2004; 1:600-607. [PubMed: 15851227]

20. Splawski I, Timothy KW, Tateyama M, Clancy CE, Malhotra A, Beggs AH, Cappuccio FP, Sagnella GA, Kass RS, Keating MT. Variant of SCN5A sodium channel implicated in risk of cardiac arrhythmia. Science. 2002; 297:1333-1336. [PubMed: 12193783] 
21. Burke A, Creighton W, Mont E, Li L, Hogan S, Kutys R, Fowler D, Virmani R. Role of SCN5A Y1102 polymorphism in sudden cardiac death in blacks. Circulation. 2005; 112:798-802. [PubMed: 16061744]

22. Akylbekova EL, Payne JP, Newton-Cheh C, May WL, Fox ER, Wilson JG, Sarpong DF, Taylor HA, Maher JF. Gene-environment interaction between SCN5A-1103Y and hypokalemia influences QT interval prolongation in African Americans: the Jackson Heart Study. AmHeart J. 2014; 167:116-122.

23. Haissaguerre M, Derval N, Sacher F, Jesel L, Deisenhofer I, de RL, Pasquie JL, Nogami A, Babuty D, Yli-Mayry S, De CC, Scanu P, Mabo P, Matsuo S, Probst V, Le SS, Defaye P, Schlaepfer J, Rostock T, Lacroix D, Lamaison D, Lavergne T, Aizawa Y, Englund A, Anselme F, O'Neill M, Hocini M, Lim KT, Knecht S, Veenhuyzen GD, Bordachar P, Chauvin M, Jais P, Coureau G, Chene G, Klein GJ, Clementy J. Sudden cardiac arrest associated with early repolarization. NEnglJ Med. 2008; 358:2016-2023.

24. Rosso R, Kogan E, Belhassen B, Rozovski U, Scheinman MM, Zeltser D, Halkin A, Steinvil A, Heller K, Glikson M, Katz A, Viskin S. J-point elevation in survivors of primary ventricular fibrillation and matched control subjects: incidence and clinical significance. J Am CollCardiol. 2008; 52:1231-1238.

25. Tereshchenko LG, McCabe A, Han L, Sur S, Huang T, Marine JE, Cheng A, Spragg DD, Sinha S, Calkins H, Stein K, Tomaselli GF, Berger RD. Intracardiac J-point elevation before the onset of polymorphic ventricular tachycardia and ventricular fibrillation in patients with an implantable cardioverter-defibrillator. Heart Rhythm. 2012; 9:1594-1602. [PubMed: 22750217]

26. Smith JG, Avery CL, Evans DS, Nalls MA, Meng YA, Smith EN, Palmer C, Tanaka T, Mehra R, Butler AM, Young T, Buxbaum SG, Kerr KF, Berenson GS, Schnabel RB, Li G, Ellinor PT, Magnani JW, Chen W, Bis JC, Curb JD, Hsueh WC, Rotter JI, Liu Y, Newman AB, Limacher MC, North KE, Reiner AP, Quibrera PM, Schork NJ, Singleton AB, Psaty BM, Soliman EZ, Solomon AJ, Srinivasan SR, Alonso A, Wallace R, Redline S, Zhang ZM, Post WS, Zonderman AB, Taylor HA, Murray SS, Ferrucci L, Arking DE, Evans MK, Fox ER, Sotoodehnia N, Heckbert SR, Whitsel EA, Newton-Cheh C. Impact of ancestry and common genetic variants on QT interval in African Americans. Circ Cardiovasc Genet. 2012; 5:647-655. [PubMed: 23166209]

27. Sutherland SE, Gazes PC, Keil JE, Gilbert GE, Knapp RG. Electrocardiographic abnormalities and 30-year mortality among white and black men of the Charleston Heart Study. Circulation. 1993; 88:2685-2692. [PubMed: 8252679]

28. Vitelli LL, Crow RS, Shahar E, Hutchinson RG, Rautaharju PM, Folsom AR. Electrocardiographic findings in a healthy biracial population. Atherosclerosis Risk in Communities (ARIC) Study Investigators. Am J Cardiol. 1998; 81:453-459. [PubMed: 9485136]

29. Olson KA, Viera AJ, Soliman EZ, Crow RS, Rosamond WD. Long-term prognosis associated with J-point elevation in a large middle-aged biracial cohort: the ARIC study. EurHeart J. 2011; 32:3098-3106.

30. Prineas RJ, Le A, Soliman EZ, Zhang ZM, Howard VJ, Ostchega Y, Howard G. United States national prevalence of electrocardiographic abnormalities in black and white middle-age (45- to 64-Year) and older (>/=65-Year) adults (from the Reasons for Geographic and Racial Differences in Stroke Study). AmJ Cardiol. 2012; 109:1223-1228. [PubMed: 22245412]

31. Walsh JA III, Prineas R, Daviglus ML, Ning H, Liu K, Lewis CE, Sidney S, Schreiner PJ, Iribarren C, Lloyd-Jones DM. Prevalence of electrocardiographic abnormalities in a middle-aged, biracial population: Coronary Artery Risk Development in Young Adults study. J Electrocardiol. 2010; 43:385-389. [PubMed: 20374967] 

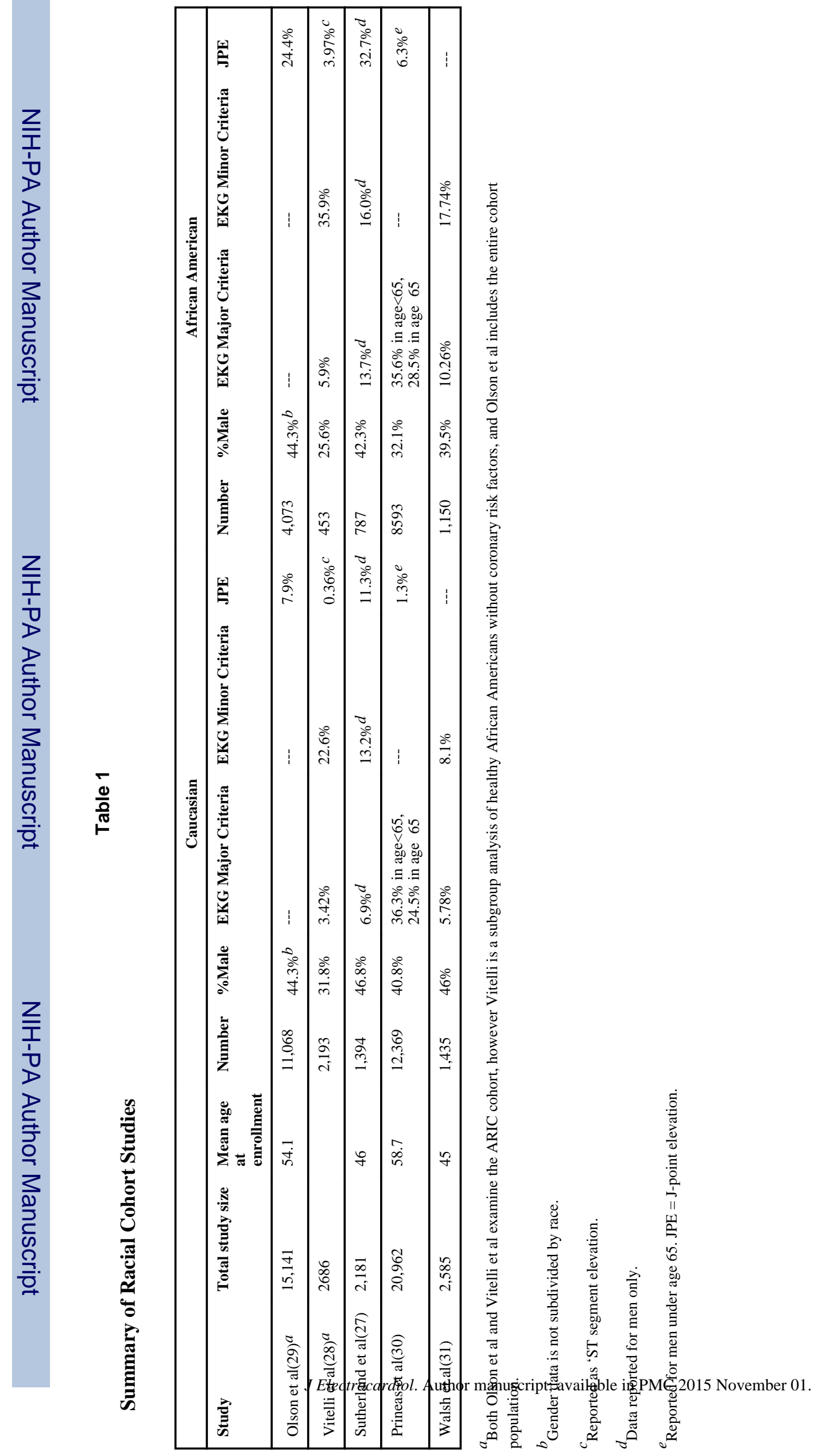